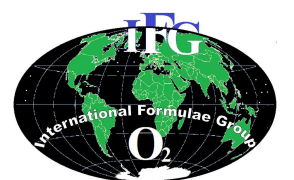

Available online at http://ajol.info/index.php/ijbes

Int. J. Biol. Chem. Sci. 9(1): 48-55, February 2015

International Joumal

of Biological and

Chemical Sciences

ISSN 1997-342X (Online), ISSN 1991-8631 (Print)

Original Paper

http://indexmedicus.afro.who.int

\title{
Effects of maternal dexamethasone exposure on hematological indices in the male offspring
}

\author{
S.O JEJE ${ }^{1,2^{*}}$ and Y. RAJI ${ }^{1}$ \\ ${ }^{1}$ Laboratory for Reproductive Physiology and Developmental Programming, \\ Department of Physiology, University of Ibadan, Ibadan, Nigeria. \\ ${ }^{2}$ Department of Human Physiology, Cross River University of Technology, \\ Okuku Campus, Cross River State, Nigeria. \\ *Corresponding author, E-mail: dhikrilat@yahoo.com, Tel: +2348086327115
}

\begin{abstract}
Maternal treatment with dexamethasone in threatening preterm delivery leads to high basal corticosterone level in the offspring. Excess glucocorticoids may inhibit the production of interleukin. This study examined the effects of prenatal and lactational dexamethasone exposure on hematological parameter in male offspring. The rats were divided into 9 groups. Group1 was administered $0.02 \mathrm{ml} / 100 \mathrm{gbw} / \mathrm{day}$ normal saline throughout pregnancy. Group 2, 3, 4 and 5 were administered $100 \mu \mathrm{g} / \mathrm{kgbw} /$ day dexamethasone through gestation day (GD) 1-7, 8-14, 15-21 and 1-21 respectively. Group 6 was administered $0.02 \mathrm{ml} / 100 \mathrm{gbw} /$ day normal saline at Lactational day (LD) 1-21. Group 7, 8 and 9 were administered $100 \mu \mathrm{g} / \mathrm{kgbw} / \mathrm{day}$ dexamethasone at LD 1-7, 1-14 and 1-21 respectively. The male offspring were sacrificed at 12 weeks of age for the evaluation of hematological indices. Results show that dexamethasone exposure at GD 1-7, 8-14 and 121 significantly $(\mathrm{P}<0.05)$ reduced $\mathrm{PCV}$, hemoglobin concentration, $\mathrm{RBC}$, platelet and neutrophil differential counts, raised eosinophil differential count relative to control. Exposure to dexamethasone at LD 1-14 and 1-21 significantly $(\mathrm{P}<0.05)$ reduced $\mathrm{RBC}$ and platelet counts but it raised $\mathrm{MCV}$ and $\mathrm{MCH}$ relative to control. This study suggests that prenatal and lactational dexamethasone administration may affect the hematological indices in the male offspring.
\end{abstract}

(C) 2015 International Formulae Group. All rights reserved.

Keywords: Dexamethasone, prenatal, lactational, hematological indices, fetal, corticosterone.

\section{INTRODUCTION}

Fetal exposure to stress and its glucocorticoids hormone mediators exerts influences on organ growth, development and subsequent offspring physiology (Drake et al., 2007). In clinical situations, sources of maternal exposure to glucocorticoids includes; maternal stress, treatment with synthetic glucocorticoids in threatening preterm delivery, treatment of medical condition such as asthma (Singh et al., 2012). Pregnant women who are at risk of delivering a child with congenital adrenal hyperplasia are also likely to receive doses of dexamethasone (a 
synthetic glucocorticoid that freely crosses the placenta) that are 60-fold higher than midgestation glucocorticoids values (Peiser et al.,2010), to reduce genital virilisation of the female fetus (Clayton and Brock, 2012).

Epidemiological studies in human and experimental studies in animal model have shown that individual tissues and whole organ systems can be programmed in utero during critical periods of development with adverse consequences on their function in later life (Fowden and Forhead, 2004). For instance, androgen dependent programming effects are usually targeted at the male programming window between gestation days 15.5-19.5 in rats (Drake et al., 2009). Recent reports have shown that exposure to maternal stress during lactation can adversely affect the maternal hypothalamic pituitary adrenal function (Tilbrook et al., 2006). This may result in altered corticosterone level in the offspring.

It has been reported in human and animal studies that early exposure to glucocorticoid could also retard growth and subsequent development of hypertension, insulin resistance, type 2 diabetes and cardiovascular disease (Drake et al., 2007). Moreover, Llorente et al. (2002) have reported that prenatal stress may decrease some immune parameters in the blood. Normally, excess glucocorticoids may inhibit the production of GM-CSF, IL-6, IL1 and TNFa (Pazirandeh et al., 2002). The effects of prenatal and lactational exposure to synthetic glucocorticoids on hematological indices have not been well reported in literature. Therefore, this study aims at evaluating the effects of prenatal and lactational dexamethasone (synthetic glucocorticoids) administration on hematological indices in Wistar rats.

\section{MATERIALS AND METHODS \\ Animal treatment}

Forty-five (45) female albino rats (150$180 \mathrm{~g}$ ) were purchased from central animal house of University of Ibadan. After two weeks of acclimatization, animals in proestrous were exposed to matured male overnight and the presence of sperm in their vaginal in the next morning mark gestation day 1 (GD1). All animal experiments were conducted in accordance with ethical norms on Animal Care and Use approved by IMRAT and Faculty of Basic Medical Sciences, College of Medicine, University of Ibadan. After pregnancy has been established, animals were randomly divided into nine groups $(n=5)$ and treated accordingly (Table 1). Administration was between 09.00 am and 10.00 am daily. Dexamethasone $(100 \mu \mathrm{g} / \mathrm{kg}$ bw/day) was administered to the treated groups and $0.02 \mathrm{ml} / 100 \mathrm{~g}$ bw/day normal saline was administered in the control. All administrations were done subcutaneously. The male offspring were allowed to grow to adulthood (12 weeks of age). Number of male offspring collected is shown in Table 1.

This study was carried out at the Department of Physiology, College of Medicine, University of Ibadan, Ibadan, Nigeria.

\section{Blood count}

Blood sample were obtained at 12 weeks of age from ocular sinus into heparinize tube for the determination of blood parameters. PCV was measured by the microhaematocrit technique using Hawsksley microhaematocrit centrifuged and spinning for $5 \mathrm{~min}$ at $12,000 \mathrm{xg}$ before reading with hematocrit reader. Hemoglobin levels were measured by the cyanomethaemoglobin method using CE 404 colorimeter (Cecil 
Instrument). The RBC, WBC and platelet counts were done by haemocytometer method. $\mathrm{MCV}, \mathrm{MCH}$ and $\mathrm{MCHC}$ were calculated indirectly by using standard formular. Differential count was done from prepared blood smear on a clean glass slide observed under light microscope.

\section{Statistical analysis}

Data are expressed as mean \pm standard error of mean ( SEM) Statistical comparisons were performed using one-way analysis of variance (ANOVA) followed by Tukey's post hoc test to compare the means of the different treatment groups. Differences between the treatment groups with a $\mathrm{p}$ - value $<0.05$ were considered significant. Data were analysed with the use of Graphpad Prism Version 5.0 for Windows (GraphPad® Software, San Diego, CA, USA.

\section{RESULTS}

Effects of prenatal dexamethasone exposure on hematological indices

Male offspring born to mother treated with $100 \mu \mathrm{g} / \mathrm{kgbw} /$ day dexamethasone (Dex) during gestation $(\mathrm{Gd})$ day 1-7, 8-14 and 1-21 shows a significant $(\mathrm{P}<0.05)$ reduction in $\mathrm{PCV}$ and RBC compared to control(Table 2). Blood hemoglobin level was also significantly reduced in the offspring born to mother treated with $100 \mu \mathrm{g} / \mathrm{kgbw} /$ day Dex during GD 1-7, 8-14 and 1-21 when compared to control and Dex Pn 15-21 (P<0.01) (Table 2). However, exposure to dexamethasone during GD 15-21 had no significant effects on PCV, $\mathrm{RBC}$, and hemoglobin level (Table 2). MCH,
MCHC and MCV were also not significantly $(\mathrm{P}>0.05)$ different in all the treated groups (Table 4).

Blood platelet count was significantly $(\mathrm{P}<0.05)$ reduced in all the treated groups when compared to control (Table 2). Total WBC count and differential count for lymphocyte were not significantly $(\mathrm{P}>0.05)$ different from control (Table 2 and 3 ). Meanwhile, differential count for neutrophil was significantly $(\mathrm{P}<0.05)$ reduced in the Dex Pn 1-21 group compared to control (Table 3). Differential counts for eosinophil was significantly higher in all the treated groups when compared to control (Table 3 ).

Effects of lactational dexamethasone exposure on hematological indices

Exposure to $100 \mu \mathrm{g} / \mathrm{kgbw} /$ day dexamethasone during lactation from Lactational day (LD) 1-14 and 1-21 significantly $(\mathrm{P}<0.01)$ reduce the $\mathrm{RBC}$ count when compared to the control and when compared to Dex LD 1-7 (Table 5). MCV and $\mathrm{MCH}$ were also significantly $(\mathrm{P}<0.01)$ higher in the Dex LD 1-14 and Dex LD1-21 group when compared to control and Dex LD1-7 groups (Table 7). MCHC level was however not significantly different in all the treated groups (Table 7). Blood platelet count was also significantly reduced in the Dex LD 1-7 $(\mathrm{P}<0.05)$ and Dex LD1-14 $(\mathrm{P}<0.01)$ groups when compared to control and when compared to Dex LD 1-21 groups (Table 5). Moreover, total WBC count and differential count are not significantly $(\mathrm{P}>0.05)$ different in all the treated groups (Table 6). 
Table 1: Treatment of animals and number of offspring collected.

\begin{tabular}{lcc}
\hline Group & Treatment & $\begin{array}{c}\text { No of male Offspring } \\
\text { included }\end{array}$ \\
\hline Control Pn & $0.02 \mathrm{ml} / 100 \mathrm{~g}$ bwt/day Normal saline (GD 1-21) & 7 \\
Dex Pn 1-7 & $100 \mu \mathrm{g} / \mathrm{kg} \mathrm{bwt/day} \mathrm{Dexamethasone} \mathrm{(GD} \mathrm{1-7)}$ & 7 \\
Dex Pn 8-14 & $100 \mu \mathrm{g} / \mathrm{kg} \mathrm{bwt/day} \mathrm{Dexamethasone} \mathrm{(GD} \mathrm{8-14)}$ & 7 \\
Dex Pn 15-21 & $100 \mu \mathrm{g} / \mathrm{kg} \mathrm{bwt/day} \mathrm{Dexamethasone} \mathrm{(GD} \mathrm{15-21)}$ & 7 \\
Dex Pn 1-21 & $100 \mu \mathrm{g} / \mathrm{kg} \mathrm{bwt/day} \mathrm{Dexamethasone} \mathrm{(GD} \mathrm{1-21)}$ & 7 \\
Control LD & $0.02 \mathrm{ml} / 100 \mathrm{~g}$ bwt/day Normal saline (PND 1-21) & 6 \\
Dex LD 1-7 & $100 \mu \mathrm{g} / \mathrm{kg} \mathrm{bwt/day} \mathrm{Dexamethasone} \mathrm{(PND} \mathrm{1-7)}$ & 6 \\
Dex LD 1-14 & $100 \mu \mathrm{g} / \mathrm{kg} \mathrm{bwt/day} \mathrm{Dexamethasone} \mathrm{(PND} \mathrm{1-14)}$ & 6 \\
Dex LD 1-21 & $100 \mu \mathrm{g} / \mathrm{kg} \mathrm{bwt/day} \mathrm{Dexamethasone} \mathrm{(PND} \mathrm{1-21)}$ & 6 \\
\hline
\end{tabular}

Dex (Dexamethasone), LD (Lactational), Pn (Prenatal)

Table 2: Effects of prenatal dexamethasone treatment on whole blood count and heamoglobin concentration.

\begin{tabular}{|c|c|c|c|c|c|}
\hline \multirow[t]{2}{*}{ Treatments } & \multicolumn{5}{|c|}{ Hematological Indices } \\
\hline & PCV (\%) & RBC $\left(10^{6} / \mathrm{ml}\right)$ & Heamoglobin (g/dl) & WBC $\left(10^{3} / \mathrm{ml}\right)$ & Platelet count $\left(10^{3} / \mathrm{ml}\right)$ \\
\hline Dex Pn 1-7 & $42.33 \pm 1.453^{*}$ & $6.98 \pm 0.29 *$ & $13.83 \pm 0.731 * * \#$ & $5450 \pm 407.23$ & $81333 \pm 982 * * * \# \# \#$ \\
\hline Dex Pn 15-21 & $46 \pm 0.5774$ & $7.67 \pm 0.13$ & $16.00 \pm 0.057$ & $5066.66 \pm 44.096$ & $57333 \pm 881 * * * \# \# \#$ \\
\hline Dex Pn 1-21 & $43 \pm 0.8165 *$ & $7.065 \pm 0.16^{*}$ & $13.36 \pm 0.338 * * \# \#$ & $5532 \pm 54.23$ & $26457 \pm 264 * * * \# \# \#$ \\
\hline
\end{tabular}


Table 3: Effects of prenatal dexamethasone treatment on differential count.

\begin{tabular}{lcccc}
\hline Treatments & \multicolumn{4}{c}{ Hematological indices } \\
\cline { 2 - 5 } & \% Lumphocyte & \% Neutrophil & \% monocyte & \% eosinophil \\
\hline Control Pn & $70.6 \pm 2.943$ & $25.8 \pm 1.456$ & $2.4 \pm 0.4$ & $1.2 \pm 0.3$ \\
Dex Pn 1-7 & $73.0 \pm 0.5774$ & $21.33 \pm 1.453$ & 3.30 .67 & $2.33 \pm 0.1$ \\
Dex Pn 8-14 & $72.0 \pm 0.632$ & $21.42 \pm 1.21$ & $2.9 \pm 0.27$ & $2.4 \pm 0.15^{*}$ \\
Dex Pn 15-21 & $71.33 \pm 0.8819$ & $23.3 \pm 1.453$ & $2.33 \pm 0.05$ & $2.66 \pm 0.3 *$ \\
Dex Pn 1-21 & $77.0 \pm 3.488$ & $18.00 \pm 3.136 *$ & $2.0 \pm 0.408$ & $3.0 \pm 0.408^{* *}$ \\
\hline *p=0.05,** $\mathrm{p}=0.01, \mathrm{n}=7$, &
\end{tabular}

Table 4: Effects of prenatal dexamethasone treatment on RBC indices.

\begin{tabular}{lccc}
\hline Treatments & \multicolumn{3}{c}{ Hematological indices } \\
\cline { 2 - 4 } & MCV $(\mathbf{f l})$ & MCH $(\boldsymbol{\rho g})$ & MCHC g/dl \\
\hline Control Pn & $61.024 \pm 0.89$ & $20.39 \pm 0.6079$ & $33.434 \pm 1.018$ \\
Dex Pn 1-7 & $60.687 \pm 0.464$ & $19.8 \pm 0.222$ & $32.637 \pm 0.5999$ \\
Dex Pn 8-14 & $61.34 \pm 0.5023$ & $20.013 \pm 0.1087$ & $32.54 \pm 0.7151$ \\
Dex Pn 15-21 & $60.81 \pm 0.6847$ & $20.276 \pm 0.3021$ & $32.503 \pm 0.8218$ \\
Dex Pn 1-21 & $61.91 \pm 0.362$ & $19.462 \pm 0.3736$ & $32.0075 \pm 0.4962$ \\
\hline \multicolumn{2}{c}{ n=7, Dex (Dexamethasone), Pn (Prenatal). }
\end{tabular}

Table 5: Effects of lactational dexamethasone treatment on whole blood count and heamoglobin concentration.

\begin{tabular}{|c|c|c|c|c|c|}
\hline \multirow[t]{2}{*}{ Treatments } & \multicolumn{5}{|c|}{ Hematological indices } \\
\hline & PCV (\%) & RBC $\left(10^{6} / \mathrm{ml}\right)$ & $\begin{array}{l}\text { Heamoglobin } \\
\text { (g/dl) }\end{array}$ & $\begin{array}{c}\text { WBC } \\
\left.10^{3} / \mathrm{ml}\right)\end{array}$ & $\begin{array}{c}\text { Platelet count } \\
\left.10^{3} / \mathrm{ml}\right)\end{array}$ \\
\hline Control LD & $35.84 \pm 1.249$ & $5.16 \pm 0.1704$ & $11.00 \pm 0.6245$ & $5.846 \pm 0.747$ & $29766 \pm 983.8$ \\
\hline Dex LD 1-7 & $33.19 \pm 1.946$ & $4.94 \pm 0.01$ & $10.13 \pm 0.7446$ & $6.12 \pm 0.6879$ & $19666 \pm 128.7 * * \#$ \\
\hline Dex LD 1-14 & $35.117 \pm 0.8967$ & $4.45 \pm 0.041 * * \#$ & $11.097 \pm 0.0664$ & $6.71 \pm 0.6505$ & $14766 \pm 956.3 * * \# \#$ \\
\hline Dex LD 1-21 & $34.69 \pm 0.2155$ & $4.37 \pm 0.1396 * * \#$ & $11.40 \pm 0.802$ & $6.307 \pm 0.8570$ & $12866 \pm 126.6^{* * \# \#}$ \\
\hline
\end{tabular}


Table 6: Effects of lactational dexamethasone treatment on differential count.

\begin{tabular}{lcccc}
\hline Treatments & \multicolumn{4}{c}{ Hematological indices } \\
\cline { 2 - 5 } & \% Lumphocyte & \% Neutrophil & \% monocyte & \% eosinophil \\
\hline Control LD & $72 \pm 4.894$ & $22.9 \pm 0.23$ & $2.4 \pm 0.4$ & $2.2 \pm 0.3$ \\
Dex LD 1-7 & $73.37 \pm 0.797$ & $21.21 \pm 0.34$ & 3.30 .67 & $2.33 \pm 0.1$ \\
Dex LD 1-14 & $71.683 \pm 0.858$ & $23.63 \pm 0.28$ & $2.9 \pm 0.27$ & $2.4 \pm 0.15$ \\
Dex LD 1-21 & $73.66 \pm 2.404$ & $22.21 \pm 0.32$ & $2.33 \pm 0.05$ & $2.66 \pm 0.3$ \\
\hline
\end{tabular}

$\mathrm{n}=6$. Dex (Dexamethasone), LD (Lactational).

Table 7: Effects of lactational dexamethasone treatment on RBC indices.

\begin{tabular}{lccc}
\hline Treatments & \multicolumn{3}{c}{ Hematological indices } \\
\cline { 2 - 4 } & MCV (fl) & MCH $(\mathbf{\rho g})$ & MCHC $(\mathbf{g} / \mathbf{d l})$ \\
\hline Control LD & $69.330 \pm 0.8819$ & $21.35 \pm 0.3926$ & $30.08 \pm 0.5696$ \\
Dex LD 1-7 & $67.00 \pm 2.309$ & $20.466 \pm 0.5175$ & $30.467 \pm 0.5239$ \\
Dex LD 1-14 & $82.00 \pm 0.5774 * * \# \#$ & $24.676 \pm 0.2233^{* * \# \#}$ & $30.06 \pm 0.1002$ \\
Dex LD 1-21 & $80.00 \pm 2.646^{*} \# \#$ & $24.733 \pm 0.8293 * * \# \#$ & $30.867 \pm 0.5548$ \\
\hline *p= 0.05,**p=0.01, \#p $=0.05, \# \# \mathrm{p}=0.01, \mathrm{~N}=6$. \\
*, shows significant different between the group and the control; \#, shows significant different between the group Dex LD \\
1-7. Dex (Dexamethasone), LD (Lactational).
\end{tabular}

\section{DISCUSSION}

The present study examined the effect of prenatal and lactational dexamethasone (synthetic glucocorticoids) exposure on hematological indices in male offspring.

Prenatal dexamethasone exposure during early, mid or throughout gestation was found to reduce PCV, hemoglobin concentration and RBC count. PCV is the variable normally used to assess the basic status of the erythron; therefore the reduced PCV may be due to reduction in the RBC production. Erythropoietin hormone stimulates the production of $\mathrm{RBC}$ and synthesis of hemoglobin (Ganong, 2005). Prenatal excess cortisol inhibits erythropoietin production in fetal sheep (Lim et al., 1996). Dexamethasone treatment of pregnant ewes in mid-term gestation decreased fetal but not adult renal erythropoietin messenger RNA (mRNA) levels (Lim et al.,1996). Thus, there is evidence that glucocorticoids may have a negative regulatory effect on erythropoietin gene expression. This may be responsible for the reduction in RBC count and hemoglobin concentration observed in this study. However, Red blood cell indices (RBC Indices) such as $\mathrm{MCV}, \mathrm{MCH}, \mathrm{MCHC}$ were not significantly affected by the prenatal dexamethasone exposure.

This study also indicates that prenatal exposure to dexamethasone in the early, mid or late gestation also leads to reduce platelet count. The reason for this is not known but it has been previously shown that plasma cortisol level is increased in offspring by the prenatal stress exposure (Kapoor et al.,2006) and excess cortisol is a potent inhibitor of cytokines such as IL 1 and 6 (Pazirandeg et al., 2002). These two cytokines stimulate erythrocytes, granulocyte, megakaryocyte cell line (Ganong, 2005). Therefore, the reduced 
platelet count may be secondary to the inhibition of IL 1 and 6.

Although, Total WBC count and differential count for lymphocyte were not significantly affected by the treatment but differential count for neutrophil was reduced in the group that was exposed to dexamethasone throughout the gestation period. In addition, differential count for eosinophil was significantly increased by the treatment. This is contrary to reduced eosinophilia following administration of glucocorticoids in asthmatic patient (Newton, 2000). The reason for this is not known, but it may be an adaptive response to stressful perinatal life. However, Newton also reported from Reichardt and Schutz, that glucocorticoids increase eosinophil proliferation and its mechanism is not well established (Newton, 2000). Similar increased in eosinophil differential count have also been reported due to maternal stress during late gestation in rats (Llorente et al., 2002).

Another important finding of this study is that administration of dexamethasone in the dams during lactation reduced the RBC count and also raises RBC indices especially MCV and $\mathrm{MCH}$ in the male offspring. It has earlier been observed that $\mathrm{MCH}$ value normally parallel the MCV value and defect in nuclear maturation as seen in megaloblastic anemia results in large oval erythrocytes with a normal hemoglobin content, the $\mathrm{MCV}$ and $\mathrm{MCH}$ are increased while the $\mathrm{MCHC}$ remain normal (Aslinia et al., 2006). It is possible that lactational dexamethasone exposure also induces this kind of defect in nuclear maturation.

Reduced platelet cell count found in this study due to lactational exposure, might also be as a result of the inhibitory effect of excess glucocorticoids on the production of platelet cell. However, dexamethasone exposure during lactation does not affect WBC count and differential count in this study.

\section{Conclusion}

This study suggests that prenatal and lactational dexamethasone administration at certain critical period of development affect hematological parameter (particularly RBC indices and platelet count) in the male offspring of exposed mother.

\section{AKNOWLEDGEMENTS}

The authors acknowledge the technical support of $\mathrm{Mr}$ Okon and $\mathrm{Mr}$ Ejiro of University of Ibadan.

\section{REFRENCES}

Aslinia F, Mazza JJ, Yale SH. 2006. Megaloblastic anemia and other causes of macrocytosis. Clin Med Res., 4(3): 236-241.

Clark PM, Hindmarsh PC, Shiell AW, Law CM, Honour JW, Barker DJ. 1996. Size at birth and adrenocortical function in childhood. Clin Endocrinol (Oxf)., 45: 721-726.

Clayton DB, Brock JW. 2012. In utero intervention forurologic diseases. Nat. Rev. Urol.. 9: 207-17.

Drake AJ, Tang JI, Nyirenda MJ. 2007. Mechanisms underlying the role of glucocorticoids in early life programming of adult disease. Clin sci., 113: 219-232.

Drake AJ, Van den SD, Scott HM, Hutchison GR, Seckl JR, Sharpe RM. 2009. Glucocorticoids amplify dibutyl Phthalate-Induced Disruption of testosterone production and male reproductive development. Endocrinology., 150: 5055-5064.

Fowden AL, Forhead AJ. 2004. Endocrine mechanisms of intrauterine programming. Reproduction, 127: 515-526.

Ganong WF. 2005. Review of Medical Physiology $\left(22^{\text {nd }}\right.$ edn). Mc Graw Hill: NY; 515-546. 
Goland RS, Jozak S, Warren WB, Conwell IM, Stark RI, Tropper PJ. 1993. Elevated levels of umbilical cord plasma corticotropin-releasing hormone in growth-retarded fetuses. J. Clin Endocrinol Metab., 77: 1174-1179.

Lim GB, Dodic M, Earnest L, Jeyaseelan K, Wintour EM. 1996. Regulation of erythropoietin gene expression in fetal sheep by glucocortiocids. Endocrinology., 137: 1658-1663.

Llorente E, Brito ML, Machado P, Gonzalez MC. 2002. Effect of prenatal stress on the hormonal response to acute and chronic stress and on immune parameters in the offspring. Journal of Physiology and Biochemistry, 58(3): 143-149.

Newton R. 2000. Molecular mechanisms of glucocorticoid action: what is important? Thorax., 55: 603-613.

Pazirandeh A, Xue Y, Prestegaard T, Jondal M, Okret S. 2002. Effects of altered glucocorticoid sensitivity in the T-cell lineage on thymocyte and T-cell homeostasis. The FASEB Journal, 16: 727-729.
Peiser P, Azziz R, Baskin LS, Ghizzoni L, Hensle TW, Merke DP, MeyerBahlburg HF, Miller WL, Montori VM, Oberfield SE, Ritzen M, White PC. 2010. Congenital adrenal hyperplasia due to steroid 21-hydroxylase deficiency: an Endocrine Society clinical practice guideline. J. Clin. Endocrinol. Metab., 95: 4133-4160.

Sarma PR., 1990. Red Cell Indices; Clinical Methods: The Histology, Physical and Laboratory Examinations ( $\left.3^{\text {rd }} \mathrm{edn}\right)$. Butter work Publisher.

Singh RR, Cuffe JSM, Moritz KM. 2012. Short and long term exposure to natural and synthetic glucocorticoids during development. Proceeding of Australian Physiological Society, 43: 57-69.

Tilbrook AJ, Turner AI, Ibbot MD, Clark IJ. 2006. Activation of the hypothalamopituitary-adrenal axis by isolation and restrain stress during lactation in Ewes: effect of presence of lamb and suckling. Endocrinology, 147(7): 35013509 . 